\title{
RNAi screens identify CHD4 as an essential gene in breast cancer growth
}

\author{
Carolina D'Alesio ${ }^{1, *}$, Simona Punzi ${ }^{1, *}$, Angelo Cicalese ${ }^{1}$, Lorenzo Fornasari ${ }^{1}$, \\ Laura Furia1, Laura Riva², Alessandro Carugo ${ }^{1,3}$, Giuseppe Curigliano ${ }^{4}$, Carmen \\ Criscitiello ${ }^{4}$, Giancarlo Pruneri ${ }^{5,6}$, Pier Giuseppe Pelicci ${ }^{1,7}$, Mario Faretta ${ }^{1}$, Daniela \\ Bossi $^{1}$, Luisa Lanfrancone ${ }^{1}$ \\ ${ }^{1}$ Department of Experimental Oncology, European Institute of Oncology, Milan 20141, Italy \\ ${ }^{2}$ Center for Genomic Science of IIT@SEMM, Fondazione Istituto Italiano di Tecnologia, Milan 20139, Italy \\ ${ }^{3}$ Department of Molecular and Cellular Oncology, UT MD Anderson Cancer Center, Houston, TX 77030, USA \\ ${ }^{4}$ Division of Experimental Therapeutics, European Institute of Oncology, Milan 20141, Italy \\ ${ }^{5}$ School of Medicine, University of Milan, Milan 20122, Italy \\ ${ }^{6}$ Biobank for Translational Medicine Unit, Department of Pathology, European Institute of Oncology, Milan 20141, Italy \\ ${ }^{7}$ Department of Oncology, University of Milan, Milan 20139, Italy \\ *These authors have contributed equally to this work
}

Correspondence to: Luisa Lanfrancone, email: luisa.lanfrancone@ieo.eu

Keywords: RNAi screen, epigenetic targets, breast cancer, CHD4, in vivo murine and human models

Received: July 22, $2016 \quad$ Accepted: September 29, $2016 \quad$ Published: October 13, 2016

\section{ABSTRACT}

Epigenetic regulation plays an essential role in tumor development and epigenetic modifiers are considered optimal potential druggable candidates. In order to identify new breast cancer vulnerabilities and improve therapeutic chances for patients, we performed in vivo and in vitro shRNA screens in a human breast cancer cell model (MCF10DCIS.com cell line) using epigenetic libraries. Among the genes identified in our screening, we deeply investigated the role of Chromodomain Helicase DNA binding Protein 4 (CHD4) in breast cancer tumorigenesis. CHD4 silencing significantly reduced tumor growth in vivo and proliferation in vitro of MCF10DCIS.com cells. Similarly, in vivo breast cancer growth was decreased in a spontaneous mouse model of breast carcinoma (MMTV-NeuT system) and in metastatic patient-derived xenograft models. Conversely, no reduction in proliferative ability of non-transformed mammary epithelial cells (MCF10A) was detected. Moreover, we showed that CHD4 depletion arrests proliferation by inducing a G0/G1 block of cell cycle associated with up-regulation of CDKN1A (p21). These results highlight the relevance of genetic screens in the identification of tumor frailties and the role of $\mathrm{CHD4}$ as a potential pharmacological target to inhibit breast cancer growth.

\section{INTRODUCTION}

Loss of function shRNA screening has become an invaluable tool in cancer research since this approach allows the identification of new genes essential in cancer maintenance and growth [1-20]. A variety of screens have been performed in different tumor types, some of which has lead to the identification of previously uncharacterized oncogenes that can be now considered potential candidates for targeted therapies [16].
Breast cancer is a heterogeneous disease, which displays diverse biological characteristics, clinical behavior and response to treatment [21]. In the context of this malignancy, the discovery of new therapeutic targets is essential since it remains the leading cause of cancer death among females worldwide. Epigenetic factors, mediating reversible changes at chromatin level, can regulate tumorigenesis, plasticity and heterogeneity of breast cancer cells [22-24], so that effective benefits of epigenetic-targeted therapy are currently investigated to obtain new-generation drugs [25]. 
The Mi-2/nucleosome remodeling and deacetylase (NuRD) complex regulates the transcription of genes involved both in normal development and in tumorigenesis, by modifying the chromatin structure through the activity of histone deacetylases [26, 27]. It has been recently shown that several members of the NuRD complex ( $R b A p 46$, $H D A C 1,2$ and MTA1-3) stimulate breast cancer formation and metastases dissemination by interacting with steroid receptors, growth factor receptors, and other cell-type specific transcriptional pathways [28-32]. Another member of the NuRD complex, the Chromodomain Helicase DNA binding Protein 4 ( $\mathrm{CHD} 4)$, has been shown to activate cell cycle transition and DNA-damage responses through distinct mechanisms [33-35]. However to date, the role of $\mathrm{CHD} 4$ in breast cancer progression has been poorly investigated.

Here, we used a human breast cancer cell line (MCF10DCIS.com), known for its capability of recapitulating the various stages of the malignancy when transplanted in an immune-compromised host [36] to perform an RNAi screen in vivo and in vitro. MCF10DCIS. com cells are endowed with metastatic potential and their tumorigenic features have been extensively characterized in vivo and in vitro $[14,36]$. We applied a conventional RNAi screen to identify epigenetic vulnerabilities in breast cancer. To this end, an shRNA, lentiviral-based library composed of chromatin modifiers has been used, as previously described [1], and CHD4 identified as a crucial gene in breast cancer development. We demonstrated that CHD4 silencing inhibits tumor growth in vivo and proliferation in vitro by strongly reducing cell cycle progression in xenografts of MCF10DCIS.com cells, in transgenic, HER2-activated, mouse model and in patientderived xenografts (PDX) of breast cancer.

\section{RESULTS}

\section{In vivo and in vitro shRNA screens in a human breast cancer cell line}

To identify novel genes that sustain breast cancer growth, we performed loss of function in vivo and in vitro shRNA screens of epigenetic regulators in a human breast cancer cell line (MCF10DCIS.com). To investigate which epigenetic modifiers favor breast cancer growth, we used two custom pooled, barcode (BC)-coupled shRNA libraries composed of 1204 and 1192 shRNAs (hEpi1 and hEpi2, respectively), targeting 236 epigenetic regulators (118 in hEpi1 and 118 in hEpi2, see Materials and Methods for details) and four control genes (Luciferase - LUC, KIF11, PSMA1 and RPL30, Supplementary Table S1) that were successfully used in an in vivo RNAi screen in melanoma [1]. MCF10DCIS.com cells were independently infected with the two libraries at low multiplicity of infection $(\mathrm{MOI}=0.2)$ so that each cell conceivably carried one single viral integrant. Ten different shRNAs were used to silence each gene. Transduced cells were either orthotopically injected into the mammary gland of immunodeficient mice (in vivo screen, $1.2^{\wedge} 10^{6}$ cells/animal, four mice $p e r$ replicate) or cultured in vitro (in vitro screen, $1.2^{\wedge} 10^{6}$ cells/plate in duplicate), so that 1000 cells represented each single shRNA (Figure 1A).

Genomic DNAs extracted from transduced cells (reference), in vitro cultured cells and tumors grown in vivo were subjected to PCR amplification and Next Generation Sequencing (NGS) for barcodes (BCs) quantification, as previously described [1] (Figure 1A). In the library, each shRNA was univocally associated to a single BC.

We first analyzed the shRNA frequency and distribution in four tumors grown in vivo. Almost all shRNAs (around 98\%) were recovered in the analyzed samples (data not shown) and the shRNA $\log _{2}$ frequency (f) showed high correlation between replicates $(\mathrm{R}>0.71$ for hEpil and $\mathrm{R}>0.68$ for hEpi2), suggesting that each tumor can represent the complexity of the whole library (Supplementary Figure S1A, S1B). We then compared the relative frequency of each shRNA per tumor to its respective reference and we calculated the $\log _{2}$ fold change (FC) of each library. The resulting distribution curves were shifted toward negative values (data not shown), suggesting that the epigenetic libraries exerted an inhibitory effect on in vivo breast cancer growth. To identify depleted genes (hits), we calculated the average of the $\mathrm{z}$-score of the $\log _{2}$ FC of every single shRNA in the four tumors and assessed the distribution of the $\mathrm{z}$-score values. We then considered depleted those shRNAs whose $\mathrm{Z}$-score value was equal or below the median of the curve and counted shRNAs depleted per gene (i.e. observed genes, Supplementary Figure S1C, S1D). To determine the minimum number of depleted shRNAs needed to score the hits and minimize the number of false positives, we applied a hypergeometric distribution, inferring the probability to find, on a set of 10 shRNA per gene (i.e. expected genes, Supplementary Figure S1C, S1D), the shRNAs scoring equal or below the median by chance $(\mathrm{P}=0.5) 0$ to 10 times. We found that the "observed genes" overcome the "expected genes" when the depleted shRNAs are either 7 (hEpi1) or 8 (hEpi2) (Supplementary Figure S1C, S1D). To select candidate hits, we decided to set the cut-off threshold at 7 depleted shRNAs per gene $(70 \%$ of the targeting shRNAs). We applied the same analysis to a pool of the above-mentioned tumors, and we observed that the resulting gene list corresponded well to that obtained by analyzing single tumors (data not shown), indicating that we can analyze tumors in pool. In order to obtain a biological triplicate, we sequenced and analyzed two more pools (4 tumors each). The scatter plots representing the shRNAs $\log _{2}(f)$ showed high correlation values among the in vivo pool replicates, ranging from $\mathrm{R}=0.82$ (Figure $1 \mathrm{~B}$, upper panel for $\mathrm{hEpi1}$ ) and $\mathrm{R}=0.75$ (Figure 1B, lower panel for hEpi2), indicating a good 
experimental reproducibility even in a high heterogeneous system such as breast cancer. The $\log _{2}$ (FC) distributions of the shRNAs in the tumor pools (mean of biological triplicate) were shifted toward negative values, as expected (Figure 1C upper panel hEpil and lower panel hEpi2, respectively). Similarly, NGS analysis of the in vitro screen showed full representation of the libraries and a perfect correlation between the shRNA $\log _{2}(f)$ of the in vitro samples $(\mathrm{R}=0.99$ : Figure $1 \mathrm{D}$, upper panel hEpi1 and lower panel hEpi2). The $\log _{2}$ (FC) distribution of the shRNAs in the in vitro duplicates (mean of replicates) followed a symmetrical distribution, as shown in Figure 1E (upper panel hEpil and lower panel hEpi2).

We generated a final list of candidate hits, considering depleted those genes whose single shRNA z-score values
(70\% of shRNAs per gene) were equal or below the median among the z-score distribution of triplicate pools in vivo or duplicates in vitro. The resulting list of depleted genes was composed of 50 and 51 genes (in vivo and in vitro respectively), 29 of which were in common between the two experimental conditions (Figure 1F). Notably, the positive control genes (KIF11, PSMA1, RPL30) and the neutral control $(L U C)$ included in the epigenetic libraries scored as expected (Supplementary Table S1).

\section{Enrichment analysis of breast cancer hits reveals gene involvement in cell cycle regulation}

We analyzed the list of the commonly depleted hits in the in vivo and in vitro settings by means of Ingenuity
A

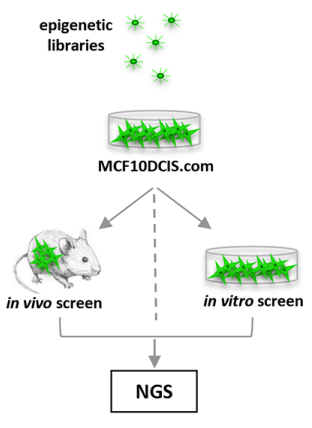

B
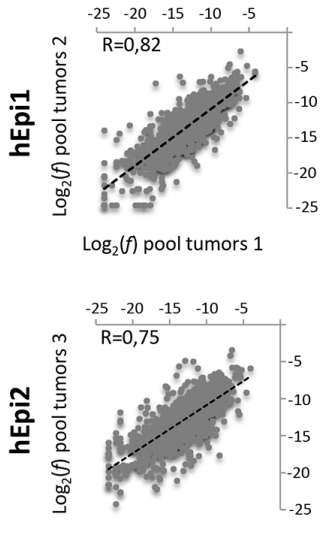

$\log _{2}(f)$ pool tumors 2
C

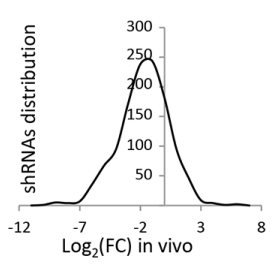

D

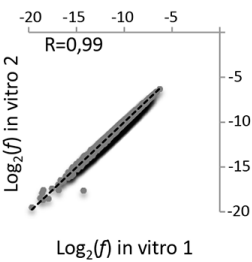

$E$
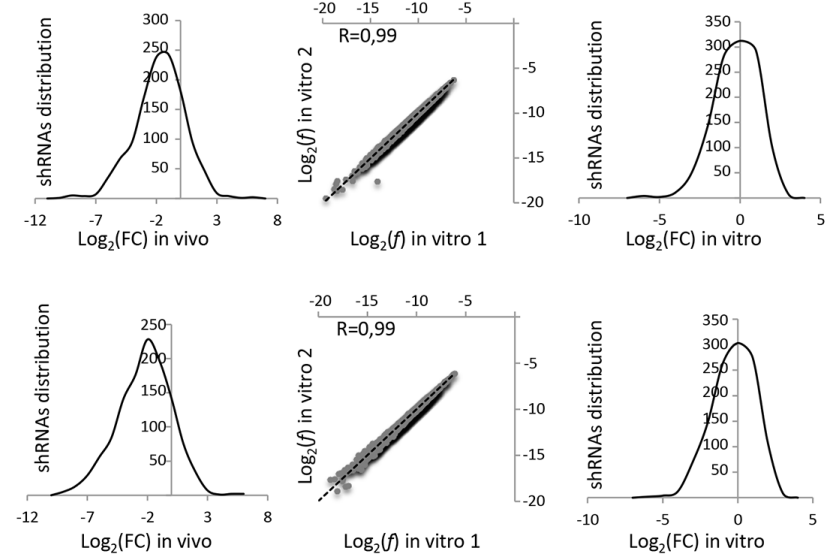

G

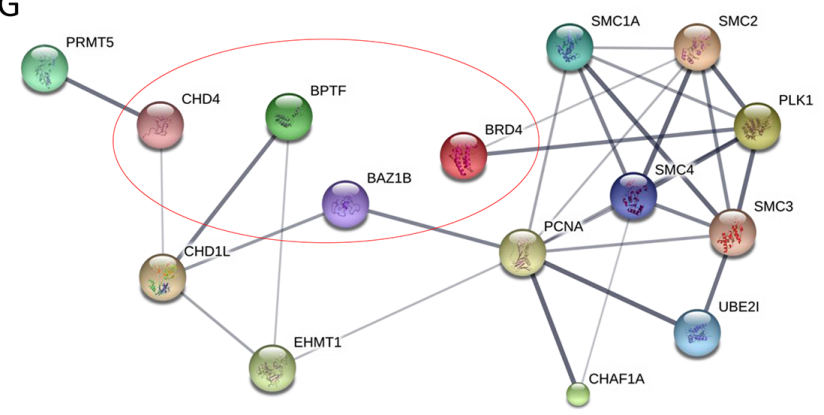

Figure 1: In vivo and in vitro shRNA screening using a human breast cancer cell line (MCF10DCIS.com). A. Graphical representation of the experimental procedure: MCF10DCIS.com cells were infected with hEpi1 and hEpi2 libraries and then orthotopically transplanted in the $4^{\text {th }}$ mammary gland of NOD/SCID mice (in vivo screen), or cultured in vitro for 21 days (in vitro screen). Genomic DNAs (gDNAs) were extracted from transduced cells as reference, tumors and in vitro cultures and subsequently subjected to PCR amplification and Next Generation Sequencing (NGS) to quantify shRNAs representation. B. Scatter plot representation of the shRNAs $\log _{2}$ frequencies $(f)$ of two different pools (pool tumors 1 and 2) composed of four tumors each of hEpil (upper panel) and hEpi2 (lower panel) transduced cells. Black dotted lines represent the axis bisectors. Pearson correlation coefficient (R) indicates the similarity between the two samples. C. Distribution of the shRNA reads expressed as $\log _{2}$ Fold Change (FC) in the three pooled samples (mean of replicates) in hEpil (upper panel) and hEpi2 (lower panel) samples. D. Scatter plot representation of the shRNAs $\log _{2}(f)$ of in vitro duplicates of hEpil (upper panel) and hEpi2 (lower panel) libraries. Black dotted lines represent the axis bisectors. Pearson correlation coefficient (R) indicates the similarity between the two samples. E. Distribution of the shRNA reads expressed as $\log _{2}(\mathrm{FC})$ of two in vitro samples (mean of replicates) of hEpil (upper panel) and hEpi2 (lower panel) transduced cells. F. Venn diagrams reporting the number of genes scoring as depleted targets in vivo, in vitro and in common between the two settings. G. Protein interaction network of 15 out of 29 genes scoring by Ingenuity Pathway Analysis and significantly enriched for "Cell cycle" regulation analyzed in STRING. Line thickness represents the strength of data confidence. Encircled genes were selected for in vivo and in vitro validation of the screen. 
Pathway Analysis (IPA) and Molecular Signature Data Base (MSigDB) software to investigate if common pathways involved in tumorigenesis can be highlighted. IPA revealed that 27 genes (out of the 29 common genes) participated in the "cancer" signature (p-values: 4.96E-02 - 2.87E-05), which is consistent with the role of epigenetic targets in research and clinical practice. 15 out of 29 genes scored as significantly enriched in the "Cell cycle" regulation $(B A Z 1 B$, BPTF, BRD4, CHAF1A, CHD1L, CHD4, EHMT1, PCNA, PLK1, PRMT5, SMC1A, SMC2, SMC3, SMC4, UBE2I) (p-values: 4.13E-02 - 7.61E-09) (Supplementary Table S1) or "DNA replication, recombination and repair" (BAHD1, BAZ1B, BPTF, BRD4, CHAF1A, CHD1L, CHD4, EHMT1, PCNA, PLK1, SIRT5, SMC1A, SMC2, SMC4, UBE2I) (p-values: 4.05E-02 - 7.61E-09) signatures (Supplementary Table S1). Genes network representation of cell cycle regulators in STRING revealed high confidence connections between the majority of the hits (Figure 1G). MSigDB analysis confirmed the implication of our candidate hits in "Cell cycle related targets of E2F transcription factors" (p-value: 2.19E-9), “G2/M checkpoint” (p-value: 2.19E-9) and "Mitotic spindle assembly" (p-value: 6.57E-6) (Supplementary Table S1). Our newly identified candidate hits show a critical role in cell cycle regulation, and their modulation promotes the development of different types of cancer [33, 37-39], breast cancer in particular [40-44].

\section{In vivo and in vitro validation of the RNAi screens}

In order to validate the in vivo and in vitro screens, we selected four candidates among the genes highly and concordantly depleted in the two screens (Supplementary Table S1). Bromodomain Adjacent to Zinc finger domain 1B $(B A Z 1 B)$, Bromodomain PHD finger Transcription Factor $(B P T F)$, Bromodomain containing 4 (BRD4) and CHD4 are key components of various epigenetic complexes implicated in cancer growth, progression and/or metastasis formation [32, 37, 45-50]. MCF10DCIS.com cells were independently infected with two pooled shRNAs of the four candidates (shRNA\#1 and \#2) or control shLUC. Silencing efficacy was measured using western blot analysis, as shown in Supplementary Figure S2A. Transduced cells were orthotopically transplanted in the mammary gland of NOD/SCID mice and tumor growth evaluated (in vivo validation). Depletion of each target significantly reduced (60-90\%) the size of the tumors, as compared to control (Figure 2A), suggesting that all candidates have an oncogenic role in breast cancer. To validate our screening in vitro, shRNA-infected MCF10DCIS.com cells were analyzed for cell proliferation, migration and clonogenic abilities, all in vitro features associated with aggressiveness and metastatic potential [51]. Silencing of each gene caused a strong decrease of cell proliferation (40-70\%) (Figure 2B), a robust reduction of migratory ability (60-80\%) (Figure 2C), and a significant drop in the clonogenic capability (60-90\%) of the cells (Figure 2D). Taken together, these results provide a robust validation of our screens, both in vivo and in vitro, suggesting that all selected hits are required for breast cancer growth.

\section{CHD4 sustains tumor growth in murine and human breast cancer models}

CHD4 is a core component of the nucleosome remodeling and histone deacetylase NuRD complex, whose function can be exploited in combination with the other proteins of the NuRD complex, as well as alone [52]. To better uncover the role of CHD4 in breast cancer maintenance, we chose the MMTV-NeuT transgenic mouse model that closely reflects some features of the aggressive human G3 breast cancer and of the human HER2 positive $(+)$ tumors $[53,54]$. Cells derived from the dissociation of spontaneously growing mammary tumors were infected using two pooled shRNAs targeting Chd4 or control scramble (SCR) shRNAs and then transplanted into syngeneic mice. CHD4 protein levels were assessed at day 0 and 8 upon infection (at the beginning and the end of the proliferation assay) (Supplementary Figure S2B). Chd4 silencing significantly reduced (about 67\%) tumor growth in vivo (Figure $3 \mathrm{~A}$ ). As for the human cell line, we investigated the effect of Chd4 inhibition on in vitro cell proliferation and migration (Figure 3B, 3C). Remarkably, knockdown of Chd4 significantly reduced MMTV-NeuT cell growth (45\%) and cell migration (46\%) compared to the control (Figure 3B, 3C), confirming that CHD4 is implicated in the development of HER2+ breast cancer, independently of the immunological context.

To investigate the effect of CHD4 in a preclinical context, we developed a human metastatic breast cancer (MBC) model by direct implantation of patient-derived tumor tissue into the mammary fat pad of NSG mice to obtain a xenograft model (PDX). PDX cells were then serially transplanted and also grown in culture to obtain short-term human cultures. PDX tumors were stained for the most common prognostic markers, i.e. Estrogen (ER), Progesterone (PgR), HER2 receptors and Ki67, to assess the epithelial origin of the tumor, its correspondence with the patient tissue and its proliferative index (Figure 3D). PDXs phenotypically recapitulated the heterogeneity of the patient tumor (manuscript in preparation) and maintained their subtype classification (MBC2 is a Triple Negative and MBC22 and MBC18 are Luminal B breast cancers). Cells derived from dissociation of PDX tumors were infected with a pool of shRNAs targeting CHD4 or neutral control ( $\operatorname{sh} L U C$ ), analyzed for silencing efficacy (Supplementary Figure S2C) and then re-transplanted in NSG mice. Notably, CHD4 silencing significantly reduced in vivo growth $(80 \%)$ (Figure 3E), confirming the role of CHD4 in growth maintenance of two different metastatic breast cancer subtypes and suggesting that $\mathrm{CHD} 4$ can be a potential druggable target also for the most aggressive diseases. 
In order to evaluate the effects of $C H D 4$ inhibition on normal tissues, we studied CHD4 silencing on the MCF10A human mammary epithelial cell line, representing the non-transformed counterpart of the MCF10DCIS.com cells, lacking tumorigenic potential in vivo and invasiveness in vitro [55]. MCF10A cells were efficiently silenced for CHD4 (Supplementary Figure S3A) and transduced cells plated for in vitro assays, as done for the corresponding MCF10DCIS. com cancer cells. Silencing of CHD4 did not significantly reduce proliferation (Supplementary Figure S3B), migration ability (Supplementary Figure $\mathrm{S} 3 \mathrm{C}$ ) and clonogenic potential (Supplementary Figure S3D), suggesting that depletion of CHD4 should be likely effective in a cancer-specific context without influencing the biological and cellular functions of normal tissues.

\section{CHD4 controls breast cancer cell cycle progression}

CHD4 knock-down can induce cell cycle arrest due to $C D K N 1 A$ up-regulation in a TP53 -dependent [33] or -independent manner [32], suggesting that it can differently regulate cell functions according to the biological context. To investigate CHD4correlated mechanisms underlying the regulation of cell proliferation in breast cancer, we decided to examine the cell cycle progression of CHD4-silenced MCF10DCIS. com cells. Flow cytometric analysis revealed that CHD4-knock-down cells prevalently accumulate in the $\mathrm{G} 0 / \mathrm{G} 1$ phase of the cell cycle (73\%) compared to control cells $(57 \%)$, with a consistent reduction of the cell population in the $\mathrm{S}$ phase $(15 \%$ in shCHD4 cells vs $27 \%$ in $\operatorname{sh} L U C$ ) (Figure $4 \mathrm{~A})$. Cell cycle deregulation

B

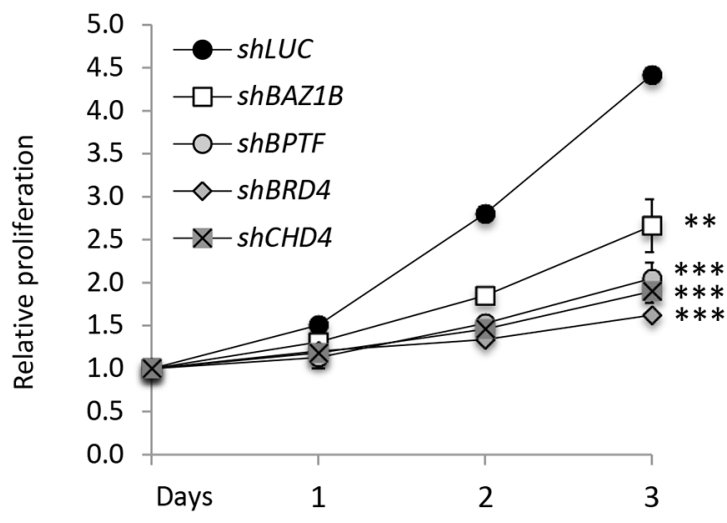

D

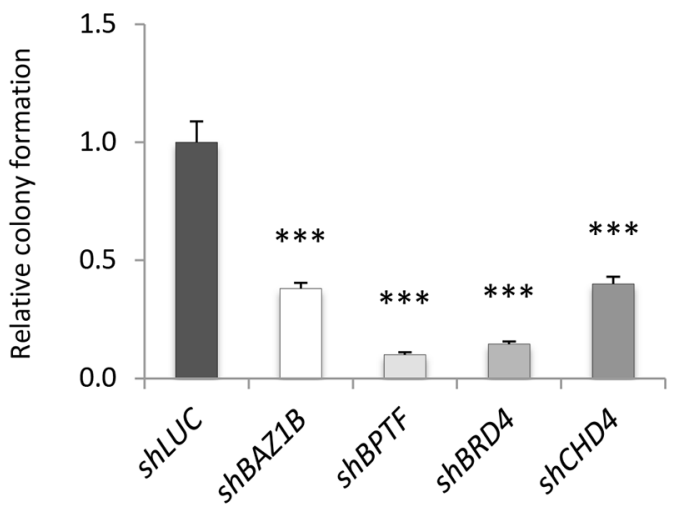

Figure 2: Validation of the shRNA screens. MCF10DCIS.com infected with two pooled shRNAs targeting the indicated genes were used for in vivo A. and in vitro B. validation. A) Transduced cells were transplanted in NOD/SCID mice. Box plots represent tumor volume $\left(\right.$ mean $\left.\pm \mathrm{SD}-\mathrm{cm}^{3}\right)$ of five to eight distinct tumors grown in vivo. B) Growth curves of shRNAs-infected cells were constructed calculating the relative proliferation values (mean $\pm \mathrm{SD}$ ) expressed as ratio of the mean luminescent values in the shRNA expressing cells compared to the control $(\operatorname{sh} L U C)$ at time of plating (Day 0). Relative migration (mean $\pm \mathrm{SD}) \mathbf{C}$. and relative colony formation D. expressed as a ratio of silenced versus control ( $\mathrm{sh} L U C$ ) values, were calculated by ImageJ analysis. Statistical significances were calculated by applying the oneway ANOVA test followed by Dunnet's post-hoc test (**: $\mathrm{P}<0.01$; ***: $\mathrm{P}<0.001)$. 
is one of the hallmark of cancer, occurring through the alteration of proteins that influence cell cycle progression at different levels [56]. CHD4 can stimulate a number of cell cycle regulators, including cyclins implicated in the G1/S transition or mitosis (cyclin A2, B1 and E2) and in the G1 phase activity (cyclin D1 and D2), and the checkpoint activation genes TP53 and CDKN1A [57]. Firstly, we investigated cyclin levels at different time points (2, 3 and 5 days after infection) in MCF10DCIS. com transduced cells. QPCR analysis showed that CHD4 depletion decreased mRNA levels of cyclin A2, B1 and E2, whereas cyclin D1 and D2 levels were not impaired (Figure 4B). PCNA mRNA was also reduced to a level similar to cyclin A2 and B1, consistently with the observed proliferation arrest (Figure 4B). It is known that TP53-CDKN1A axis directly and indirectly regulates cell cycle progression [58] and controls G1/S transition modulating cyclins levels [59]. Western blot analysis performed in MCF10DCIS.com transduced cells revealed that the reduction of $\mathrm{CHD} 4$ did not increase TP53 protein level and its Serine-15 phosphorylation at different time points (2, 3 and 5 days after infection), but it determined a substantial up-regulation of CDKN1A protein level (Figure 4C) since the early time point (2 days since infection) of the experimental assay. Taken together, this data suggest that $\mathrm{CHD} 4$ silencing increases CDKN1A content, decreases A2, B1 and E2 cyclin levels and arrests the cells in the G0/G1 phase of cycle
A

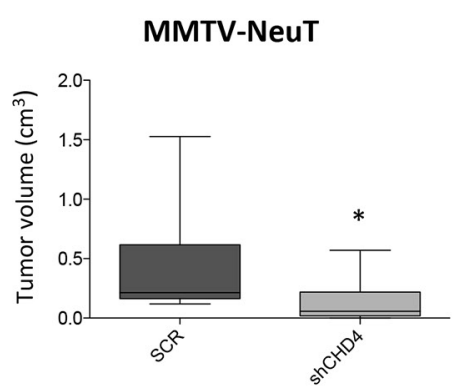

D

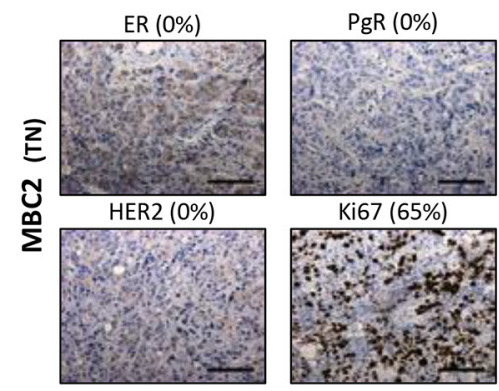

$\mathrm{E}$

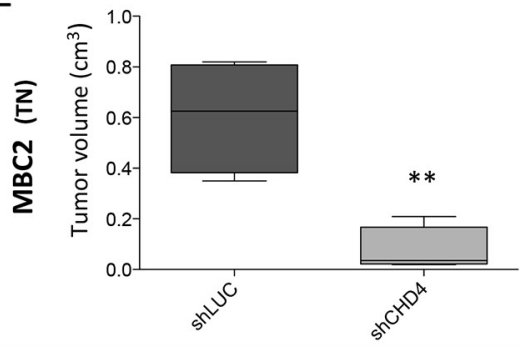

B
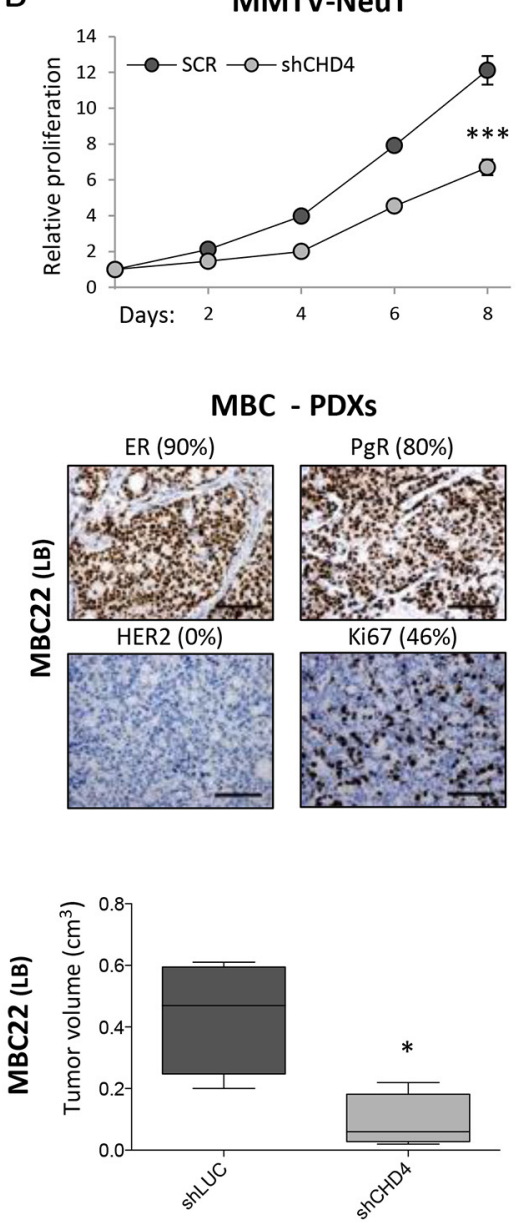

C
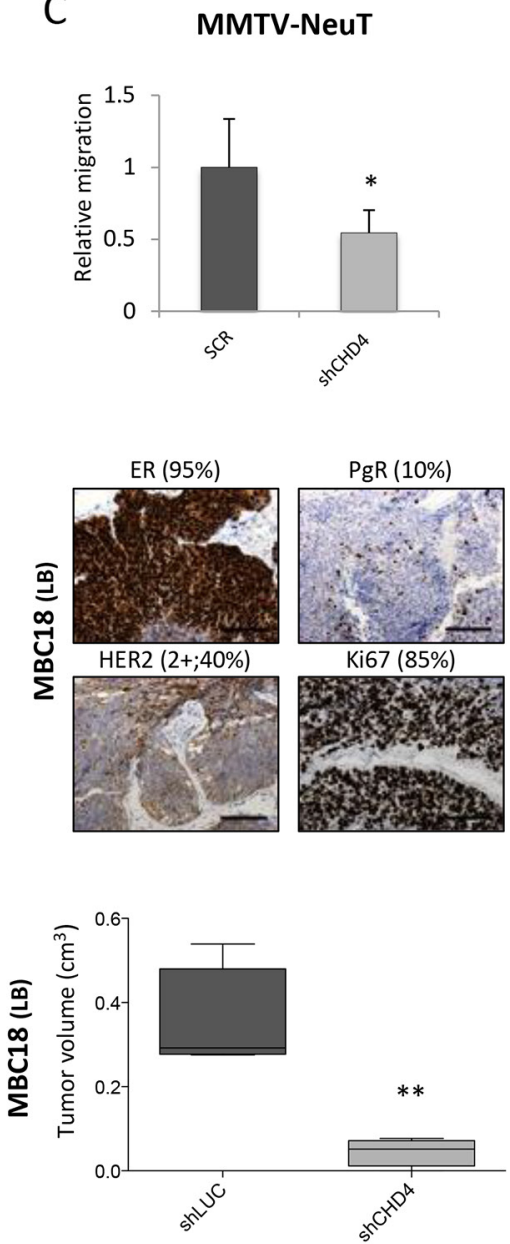

Figure 3: CHD4 role in the MMTV-NeuT transgenic mouse and in PDX breast cancer models. A. Cells derived from dissociation of spontaneous mammary tumors of MMTV-NeuT mice were infected with two pooled shRNAs silencing Chd4 gene and a corresponding control (scramble - SCR) and subsequently transplanted in FVB mice. Box plots represent the tumor volume (mean \pm SD $\mathrm{cm}^{3}$ ) of eight to ten distinct tumors grown in vivo. Statistical difference between groups was calculated using Mann-Whitney $\mathrm{U}$ test (U=14.0; *: $\mathrm{P}<0.05$ ). Transduced cells were also used to analyze in vitro cell proliferation (eight days) B. and migration $\mathbf{C}$. Statistical significance was calculated by applying a Student $t$-test $(*: \mathrm{P}<0.05 ; * * *: \mathrm{P}<0.001)$. D. Immunohistochemical staining of Estrogen (ER), Progesterone (PgR), HER2+ receptors and Ki67 in three metastatic breast cancer (MBC) patient-derived xenografts (PDXs). Percentage (\%) of positive cells is reported for each staining. Scale bar: $100 \mu \mathrm{m}$. E. Box plots representing tumor volume (mean $\pm \mathrm{SD}-\mathrm{cm}^{3}$ ) of four distinct tumors arisen after transplantation of PDXs cells infected with a pool of two shRNAs targeting CHD4 and the corresponding control (sh $L U C$ ) in NSG mice. Statistical significance was calculated by applying a Student $t$-test $(*: \mathrm{P}<0.05 ; * *$ : $\mathrm{P}<0.01)$. 
progression rather than inducing apoptosis through the activation of caspases (data not shown).

To contextually analyze the effect of $C H D 4$ and its putative effectors in breast cancer cell cycle progression, we took advantage of a more quantitative and sensitive technique, the A.M.I.C.O. (automated microscopy for image cytometry) technology, which allowed us to perform a multi-parameter analysis, targeting specific cell subpopulations [60, 61]. To analyze effects of CHD4 downregulation on proliferation ability, cell cycle progression and regulation we simultaneously assessed the level of i) CHD4, ii) Ethinyl-deoxyUridine (EdU), for active DNA synthesis detection, iii) Ki67, as a proliferation marker, and iv) TP53 and CDKN1A, to monitor checkpoint activation, in relation to DNA content. We transiently transfected MCF10DCIS.com cells with two different siRNAs targeting CHD4 (siCHD4-1 and siCHD4-2), the pool of the two siRNAs (siCHD4-pool) or siRNA Luciferase ( $\mathrm{si} L U C$ ) as control. We first confirmed that $C H D 4$ was efficiently silenced evaluating its content with respect to DNA in different cell populations ( $\mathrm{si} L U C$, siCHD4-1, siCHD4-2, siCHD4-pool). CHD4 transfected cells showed low CHD4 levels in comparison to neutral controls (Supplementary Figure S4A, S4B). We evaluated DNA profiles and DNA synthesis by EdU content analysis in MCF10DCIS.com cells confirming a robust cell cycle arrest in the G0/G1 phase of CHD4-silenced cells (Figure 5A). Furthermore, loss of CHD4 significantly reduced the $\mathrm{S}$ phase of breast cancer cells (16-19\%) (Figure 5A). The effect of CHD4 knock-down on proliferative ability of the cells was further confirmed by the evaluation of the number of acquired events measured as cellular density in all conditions examined. In fact, a lower number of events were acquired for $\mathrm{CHD} 4$ silenced cells due to a reduced proliferative capability (Figure 5A). The effect of CHD4 knock-down on proliferation was further confirmed by the evaluation of the number of acquired events, as a measure of cellular spatial density. In fact the imaged area being equal, a lower number of events was acquired for CHD4 silenced cells due to a reduced capability of these cells to proliferate (Figure 5A). In agreement with the above observation, the analysis of Ki67 content in the cells interfered for CHD4 (Figure 5B) revealed a drastic reduction (25-49\%) in the actively proliferating fraction compared to control population. Arrested cells were blocked in the G0 phase [62] with a
A
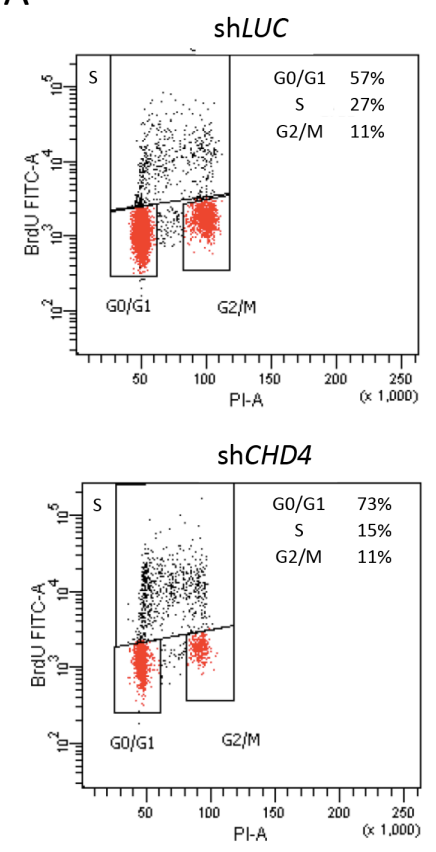

B

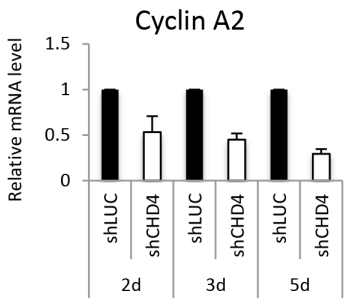

Cyclin D1
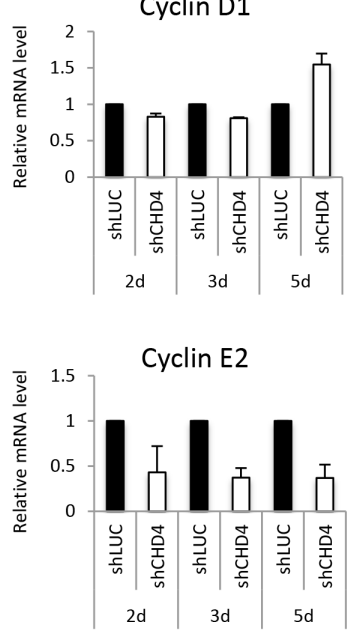

Cyclin B1

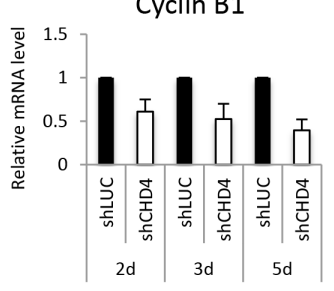

Cyclin D2
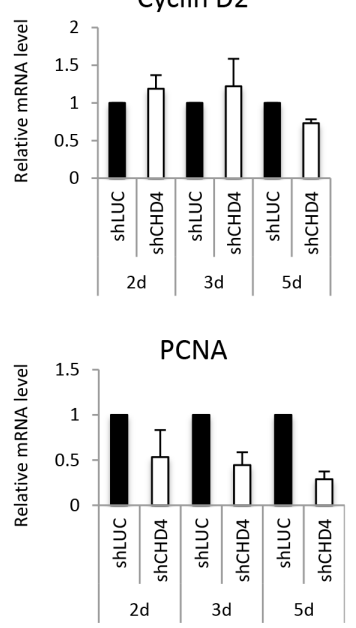

C
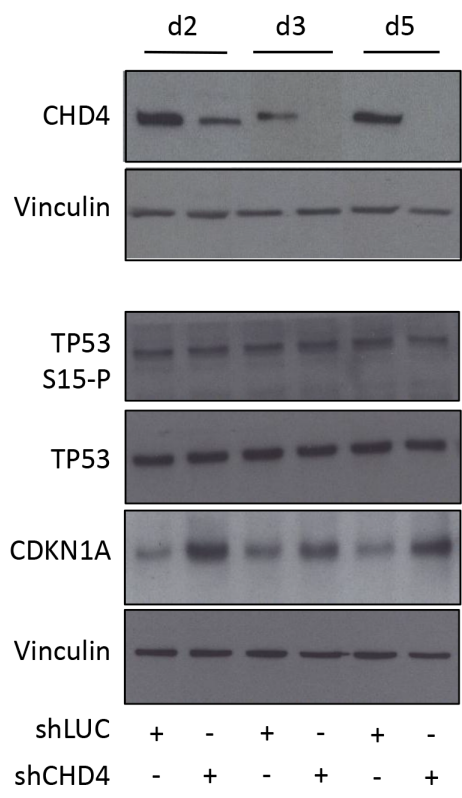

Figure 4: CHD4 function in MCF10DCIS.com cell cycle progression. A. MCF10DCIS.com cells were infected with shCHD4 or control $(\mathrm{sh} L U C)$ and after 5 days analyzed by flow cytometry for Bromodeoxyhuridine (BrDU) and PI content. Percentage (\%) of cell population in each phase of cell cycle $(\mathrm{G} 0 / \mathrm{G} 1, \mathrm{~S}$ and $\mathrm{G} 2 / \mathrm{M})$ is reported within the panels. B. Effect of CHD4 silencing on the regulation of different genes controlling cell cycle progression and proliferation was detected by qPCR analysis at different time points (days $-\mathrm{d}$ ) from infection. Histograms represent mRNA levels (mean $\pm \mathrm{SE}$ of two independent experiments) of cyclin A2, cyclin B1, cyclin D1 and D2, cyclin E2, PCNA in MCF10DCIS.com cell line. RPLP0 was used as housekeeper. C. Total TP53, phospho-TP53 (serine15) and CDKN1A levels were analyzed, at different time points (days - d) from infection, by western blot in MCF10DCIS.com cells infected with shCHD4 and the control $\operatorname{sh} L U C$. Vinculin was used as normalizer. 
complete exit from cell cycle well before the completion of the G1 phase.

Quite strikingly, analysis on TP53 content revealed no modification of TP53 level upon CHD4 silencing in comparison to control cells (Figure 5C), confirming that TP53 is not required to maintain G0 arrest. As a further confirmation of this data, the CHD4 knocked down population was subdivided in $\mathrm{CHD} 4$ positive ( $\mathrm{CHD} 4+$, with $\mathrm{CHD} 4$ residual expression) and negative (CHD4-) cells. The analysis of TP53 content showed a similar distribution in both subpopulations (Supplementary Figure S4C).

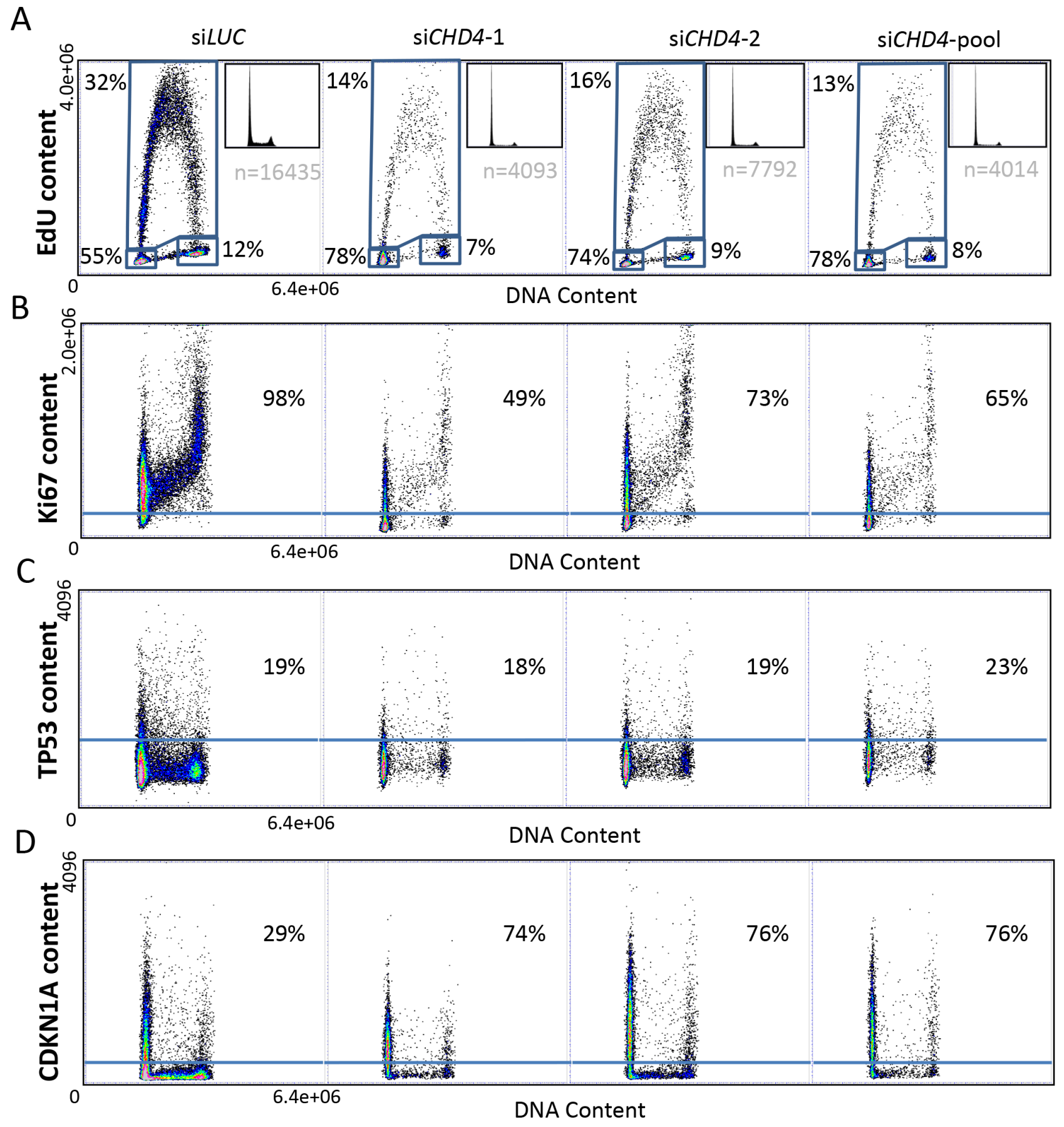

Figure 5: Cell cycle progression, proliferation index and checkpoint activation analysis by high-content and highresolution multiparameter image cytometry. MCF10DCIS.com cells were transfected with two separate (siCHD4-1 and siCHD4-2) or pooled (siCHD4-pool) siRNAs against $C H D 4$ or the control ( $\operatorname{si} L U C$ ). DNA content (x-axis) was correlated to the analyzed parameter (y-axis): EdU A. Ki67 B. TP53 C. CDKN1A D. content. Percentages of cells in each phase of cell cycle are reported with respect to the total cell population (A). Ki67 (B), TP53 (C) and CDKN1A (D) content are expressed as percentage with respect to the gated cell population. 
Finally, analysis of CDKN1A levels in MCF10DCIS.com cells revealed a strong increase of CDKN1A content $(45-47 \%)$ in the CHD4 depleted cells, compared to neutral control (Figure 5D). Almost all silenced cells (CHD4-) showed a dramatic upregulation of CDKN1A in comparison to CHD4+ cells (Supplementary Figure S4D) confirming that the downregulation of CHD4 causes a consistent cell cycle arrest and a consequent proliferation loss due to a significant up-regulation of $C D K N 1 A$ level.

\section{DISCUSSION}

Despite impressive improvements in breast cancer survival over the last decades, a not negligible number of patients still relapse as consequence of resistance to conventional treatment [63]. Therefore, the identification of new druggable genes involved in tumorigenesis must be considered of utmost importance. Here we show that we have identified novel epigenetic targets by means of an RNAi screen performed in vivo and in vitro in the MCF10DCIS.com cell line.

We took advantage of a published protocol in which MCF10DCIS.com cells were screened with a metabolic library composed of 516 shRNAs [14]. Although we increased the number of shRNAs composing each library (see Materials and Methods for details), we were able to represent the complexity of the system and contextually reduce the possibility of detecting false positive depleted genes, as more shRNAs were included in the analysis.

Our in vitro and in vivo approach allowed us to compare the two conditions and take into considerations those genes whose activity interferes with tumor growth either in vivo or in vitro. Approximately 50\% of the genes that we found depleted in the two screens were common to the two conditions, suggesting that the regulation of epigenetic pathways in breast cancer relays on mechanisms that can be uncovered in the two contexts. Moreover, IPA showed that a relevant proportion of these genes are implicated in the control of cell cycle progression.

We have fully validated the epigenetic screens in vivo and in vitro by analyzing four different hits and we have demonstrated that BAZ1B, BPTF, BRD4 and CHD4 are essential for breast cancer growth. In particular, it has already been demonstrated that $C H D 4$, together with the other subunits of the NuRD complex, is implicated in tumor progression $[32,48,64]$, but up to now no data were available in breast cancer. In our system, CHD4 silencing significantly reduces cell proliferation and migration both in vivo and in vitro, suggesting that CHD4 inhibition can be important to block cancer progression.

Because of the complexity and heterogeneity of breast cancer, it seems crucial to set up appropriate preclinical systems to fully investigate the different aspects of this disease. Therefore, an integrated and multisystems approach is currently the strongest way to model this disease and to study gene vulnerabilities [65].

Since the human in vivo shRNA screen has been performed in immunodeficient animals, we investigated the role of CHD4 in a model in which tumor develops in the presence of an intact immune system. In vivo and in vitro silencing of CHD4 in the MMTV-NeuT model revealed that it plays a crucial role also in a fully immunecompetent system, meaning that the tumorigenic function of CHD4 can bypass the intrinsic immune surveillance. Concerning the oncogenic role of $C H D 4$ in HER2+ breast cancer, it seems likely that targeting CHD4 in HER2+ patients can be a valuable strategy to overcome resistance to approved drugs [66-68]. To explore the role of $C H D 4$ in patients, we used PDX models of Luminal B and Triple Negative breast cancer. The dramatic reduction of tumor growth induced by the loss of CHD4 is extremely relevant and suggests that the pharmacological inhibition of this gene could improve the treatment of the most aggressive breast cancer subtype.

Despite the high selectivity of targeted therapy, unpredictable side effects and toxicity in normal cells can emerge [69]. Therefore it is extremely important to test the effects of CHD4 silencing on normal cells. We showed that CHD4 depletion did not influence the proliferative, migratory and clonogenic potential of the non-transformed MCF10A cells, suggesting that CHD4 is selectively responsible of cell survival and proliferation in cancer cells only.

With this work, we shed light on the mechanisms through which CHD4 stimulates breast cancer cell proliferation. Noticeably, for the first time, we show that CHD4 is an essential gene in breast cancer progression. In particular, cell cycle analysis showed that the loss of CHD4 causes MCF10DCIS.com cells to arrest in G0 phase, with a dramatic reduction of proliferation and a striking reduction of DNA synthesis. Loss of CHD4 arrested the cells well before the G1/S transition as demonstrated by the selective loss of Ki67 proliferation marker. Differently to U2OS cells, where cycle progression is regulated in a TP53-dependent manner [33], our results suggest that $C H D 4$ can suppress cell cycle progression through $C D K N 1 A$ up-regulation in breast cancer cells.

It has been shown that oncogenic $R A S$, as well as $R A F$, one of its downstream effectors, activates CDKN1A transcription through both TP53-dependent and TP53-independent mechanisms, the second one requiring the transcription factor E2F1 [70]. MCF10DCIS.com cells contain an active HRAS and for this reason, the $E 2 F 1$ binding activity, as well as $H R A S / C H D 4 / E 2 F 1$ axis, will be actively investigated in these cells.

In conclusion, our approach identifies diverse epigenetic targets as crucial oncogenes in breast cancer, 
suggesting in particular that CHD4 targeting can be used as an efficient strategy to arrest breast cancer progression.

\section{MATERIALS AND METHODS}

\section{Libraries and plasmids and siRNAs}

\section{Libraries}

Human epigenetic libraries were purchased from Cellecta Inc. and engineered into the pRSI-U6-(sh)-UbiCGFP-2A-Puro lentiviral vector containing the puromycinresistance and the GFP fluorescent marker. shRNAs were under the control of a constitutive U6 promoter and univocally associated to a barcode cassette (BC) of 18 degenerated, non-overlapping nucleotides. The libraries contained 1204 (hEpi1) and 1192 shRNAs (hEpi2) targeting 118 (hEpi1, 10 different shRNAs per gene) and 118 (hEpi2, 9 or 10 different shRNAs per gene) epigenetic genes, three positive (KIF11, PSMA1, RPL30) and one neutral (Luciferase, $L U C$ ) controls.

\section{Plasmids}

Each shRNA was cloned into the pRSI-U6-(sh)UbiC-TagRFP-2A-Puro vector (Cellecta Inc.) and as pool of two shRNAs was used to infect target cells. Complete sequences of shRNAs used for validation experiments are reported in Supplementary Table S1. shRNAs targeting mouse genes were engineered into the pLKO. 1 vector (Sigma). 3 scrambles shRNAs were pooled together and used as neutral control (SCR). The shRNAs targeting Chd 4 were used as pool of two distinct shRNAs. Complete sequences of shRNAs and control are provided in Supplementary Table S1.

\section{SiRNAs}

siMax siRNA 21 mers, obtained from Eurofin Genomics, were used for the gene silencing of $L U C$ (5'-UACGACGAUUCUGUGAUUU-3') as control and CHD4 (siRNA sequences - siCHD4-1: 5'-CCCAG AAGAGGAUUUGUCA-3' and siCHD4-2: 5'-GGUUU AAGCUCUUAGAACA-3'). siRNAs targeting CHD4 were also used in pool.

\section{Cell cultures and infection}

MCF10DCIS.com (obtained from Wayne State University, 5057 Woodward Avenue, Detroit Michigan) and MCF10A (obtained from NIH Institute and authenticated in house by Gene Print 10 System, Promega) cell lines were maintained in their respective media as recommended by suppliers. MMTV-NeuT cells were obtained from dissociation of tumors following protocol described in www.stemcell.com. Human metastatic breast cancer (MBC) xenografts were obtained by direct implantation of patient-derived tumor tissue into the mammary fat pad of NOD.Cg-Prkdc ${ }^{\text {scid }}$ $\mathrm{I} 2 \mathrm{rg}^{\mathrm{tm} l \mathrm{Wj}}{ }_{\mathrm{jl}} / \mathrm{SzJ}$ mice (NSG). Patient-derived xenografted tumors (PDXs) were then serially re-transplanted to generate secondary tumors. PDX cells were obtained by enzymatic digestion and mechanical dissociation (Miltenyi Biotec) of tumors and grown in culture to obtain short-term human cultures. MMTV-NeuT and PDX cells were maintained in DMEM/F12 (1:1, Lonza/ Gibco) supplemented with 10\% Standard Fetal Bovine Serum (FBS) (HyClone, GE Healthcare Life Science), $10 \mathrm{mM}$ HEPES (Sigma), $5 \mu \mathrm{g} / \mathrm{mL}$ insulin (Roche), 0.5 $\mu \mathrm{g} / \mathrm{mL}$ hydrocortisone (Sigma), $20 \mathrm{ng} / \mathrm{mL}$ (MMTVNeuT cells) or $10 \mathrm{ng} / \mathrm{mL}$ (PDXs cells) epidermal growth factor (EGF, Tebu-Bio), $10 \mathrm{ng} / \mathrm{mL}$ (MMTV-NeuT cells) or $50 \mathrm{ng} / \mathrm{mL}$ (PDXs cells) Cholera Toxin (Sigma). Concentrated lentiviral particles (TU, transducing units) from libraries or single plasmids were either purchased by Cellecta Inc. or produced by transfecting $293 \mathrm{~T}$ cells, as described in the Cellecta User Manual (http://www.cellecta.com/wp-content/uploads/CellectaManual-13Kx13K-Barcode-Library-v1c.pdf). Lentiviral particles were added to MCF10DCIS.com, MCF10A, MMTV-NeuT or PDX short term cultures, together with $4 \mu \mathrm{g} / \mathrm{mL}$ polybrene (Sigma) for 16 hours. After 48 hours medium was replaced and $3 \mu \mathrm{g} / \mathrm{mL}$ of puromycin was added for 72 hours before performing the experiments. Library infection was performed on MCF10DICS. com cells using a Multiplicity of Infection (MOI) of $\sim 0.2 \mathrm{TU} /$ cell. Conversely, in the in vivo validation and in vitro studies, cells were infected at high MOI (MCF10DCIS.com and MCF10A cells at MOI of $\sim 3$, MMTV-NeuT at MOI of $\sim 20$ and PDX culture cells at MOI of $\sim 50$ with pooled shRNAs silencing specific target genes).

\section{Animals}

Non-obese diabetic/severe combined immunodeficiency (NOD/SCID) mice and Friend Virus B-Type (FVB) were purchased from Harlan Laboratories. NSG mice were purchased from Charles River. MMTV-NeuT transgenic mice were in the FVB background [71]. Only female mice 6-12 weeks old (15-20 gr weight) were used for experimental procedures.

\section{Ethics statement}

Investigation has been conducted in accordance with the ethical standards and according to national and international guidelines. In vivo studies were performed after approval from our fully authorized animal facility, notification of the experiments to the Ministry of Health (as required by the Italian Law)(IACUCs $\mathrm{N}^{\circ} 757 / 2015$ ) and in accordance to EU directive 2010/63. Human tissue biopsies were collected from patients whose informed consent was obtained in writing according to the policies 
of the Ethics Committee of the European Institute of Oncology and regulations of Italian Ministry of Health. The studies were conducted in full compliance with the Declaration of Helsinki.

\section{In vivo and in vitro shRNA screens}

$1.2^{\wedge} 10^{6}$ MCF10DCIS.com cells transduced with epigenetic libraries were orthotopically injected in the $4^{\text {th }}$ mammary gland of 12 NOD/SCID mice, or plated in duplicate in vitro. Reference cells, cells cultured for 21 days [72] and tumors harvested 28 days after transplantation [14] were subjected to DNA extraction. BCs representation was measured by Next Generation Sequencing (NGS) on Illumina HiSeq2000 and BCs were identified by aligning each sequencing read to the barcoded-libraries using the Bowtie aligner [73], and by considering only those BCs having, at most, three mismatches in each alignment. Detailed procedures of the analysis of the screen are described in Results. gDNA extraction, PCR assay and NGS were performed according to what reported in the Cellecta User Manual.

\section{In vivo study}

MCF10DCIS.com, MMTV-NeuT and PDX cells were infected with control shRNA ( $\operatorname{sh} L U C)$ and pooled shRNAs silencing specific target genes (see main text). $2.5^{\wedge} 10^{5}$ infected MCF10DCIS.com or PDX cells and $5^{\wedge} 10^{5}$ infected MMTV-NeuT cells were orthotopically injected into the $4^{\text {th }}$ mammary gland of 4 to 8 mice (respectively NOD/SCID, NSG or FVB). Tumor volume was calculated using this formula: $V=1^{2 \wedge} \mathrm{L} / 2$ (1 length; $\mathrm{L}$ width).

\section{In vitro studies}

\section{Proliferation assay}

$2^{\wedge} 10^{3}$ MCF10DCIS.com or MCF10A infected cells were plated in triplicate (see above) and cell proliferation was measured by CellTiter-Glo assay (Promega). $8^{\wedge} 10^{4}$ MMTV-NeuT infected cells were plated in triplicate and counted every 48 hours.

\section{Migration assay}

The migration assay was performed using $8.0 \mu \mathrm{m}$ pore size inserts in 24 -well plates. Triplicates of $2.5^{\wedge} 10^{5}$ MCF10DCIS.com cells were seeded in the upper chamber in $0.5 \%$ horse serum and complete medium supplemented with $50 \%$ FBS were added as chemoattractant in the lower chamber [74]. $5^{\wedge} 10^{4}$ overnight starved $(1 \%$ horse serum) MCF10A cells were seeded in the upper chamber and complete medium was added in the lower chamber. After 24 hours of incubation, migrated cells were fixed in $10 \%$ methanol and stained with $0.5 \%$ Crystal Violet. Migration was quantified by ImageJ analysis. Triplicates of $1^{\wedge} 10^{5}$ MMTV-NeuT cells in growth factors and serum free medium were seeded in the upper chamber and complete medium supplemented with 50\% FBS was used as chemoattractant. After 24 hours of incubation, cell migration was quantified as described previously.

\section{Colony formation assay}

Clonogenic potential of $1^{\wedge} 10^{3}$ MCF10DCIS.com and MCF10A cells was measured in triplicates. After 7 days of culture, colonies were fixed, stained and counted as described above.

\section{Immunohistochemistry}

Tumor fragments from PDXs were formalin-fixed and paraffin-embedded. After deparaffinization, sections were treated with $1 \mathrm{mM}$ EDTA buffer $(\mathrm{pH}=8)$ for $30 \mathrm{~min}$ at $95^{\circ} \mathrm{C}$, followed by incubation with $3 \%$ hydrogen peroxide in distilled water for $5 \mathrm{~min}$ at RT. Sections were stained with monoclonal anti-estrogen (ER) (Dako, clone 1D5); monoclonal anti-progesterone (PgR) (Dako, clone PgR 636); polyclonal anti-ErbB2 (Dako-A0485); monoclonal anti-Ki67 (Dako, clone MIB-1). Images were acquired by OLYMPUS BX51 up-right (objective UPIanAPO 20x/0,85) connected to Nikon Color Camera Digital Sight DS-U1 (software NIS-elements).

\section{Cell cycle analysis}

\section{BrdU content analysis}

5 days post shRNA infection ( $\mathrm{sh} L U C$ and shCHD4), MCF10DCIS.com cells were pulsed with $5 \mathrm{mM}$ Bromodeoxyuridine (BrdU), fixed and stained against BrdU (BD Biosciences). Pellet cells were stained with secondary antibody, incubated with propidium iodide (PI) and RNase $\mathrm{A}$ and then acquired by fluorescent-activated cell sorting (FACS) at FACS Canto II (BD Bioscience). Analysis was performed using FlowJo 9.3-2 analysis software.

\section{Multiparameter image cytometry}

MCF10DCIS.com cells were transfected with siMax siRNA 21 mer silencing $L U C$ or CHD4 (as single siRNA: siCHD4-1 and siCHD4-2 and pooled siRNA: siCHD4pool) using Lipofectamine RNAiMAX reagent (Life Technologies, 13778-075). After 72h, cells were pulsed with $10 \mu \mathrm{M}$ EdU (a synthetic nucleotide to identify DNAreplicating cells), fixed and stained against CHD4 (SigmaHPA012008), Ki67 (BD Pharmigen-558615), TP53 (Santa Cruz-sc6243), CDKN1A (Dako-M7202) and EdU (Click-iT ${ }^{\mathrm{TM}}$ Imaging kit; Life Technologies), according to manufacturer instructions. Images were collected by a BX61 fully motorized Olympus fluorescence microscope controlled by $\mathrm{Scan}^{\wedge} \mathrm{R}$ software. An oil immersion $60 \mathrm{X} 1.3$ NA objective was employed for acquisition. Cell cycle statistical analysis was performed as described by Furia and colleagues [61]. 


\section{Quantitative RT-PCR (qPCR)}

Total RNA was extracted from MCF10DCIS.com cells infected with shCHD4 and $\operatorname{sh} L U C$ using the QuickRNA MiniPrep kit ZymoResearch and reverse transcribed using EasyScript Plus Reverse Transcriptase and EasyScript Plus cDNA Synthesis kit. Quantitative RT-PCR analyses were done in triplicate on the Applied Biosystems 7500 Fast Real-Time PCR System with the fast-SYBR Green PCR kit as instructed by the manufacturer (Applied Biosystems). The transcription level of RPLP0 was used as housekeeper.

\section{Western blot analysis}

MCF10DCIS.com, MCF10A, MMTV-NeuT and PDX cells were lysed in RIPA buffer supplemented with protease inhibitors (Roche). Protein extracts were resolved on SDS-polyacrylamide gel, blotted onto nitrocellulose membranes and probed with antibodies against Vinculin (Sigma V9131), BAZ1B (Abcam ab51256), BRD4 (Abcam ab128874), CHD4 (Abcam ab70469), BPTF (Novus Bio-NB100 41418). Membranes were incubated with appropriate secondary antibodies linked to horseradish peroxidase. Blots were then developed with the ECL system according to manufacturer's protocols and acquired by VueScan 9 x 32 (9.0.89). Images have been cropped at specific protein band of interest to improve the clarity of data presentation.

\section{Gene set enrichment analysis and protein interaction}

The list of candidate hits scored in the in vivo and in vitro settings was uploaded to the Ingenuity Pathway Analysis (IPA) software (Qiagen, Valencia, CA) and IPA core analysis was run to analyze pathways and genes interaction scoring at high significance. Gene list was also investigated in Molecular Signature Data Base, MSigDB (http://software.broadinstitute.org/gsea/msigdb/annotate. jsp), applying "Compute Overlaps" tool and "Hallmark gene sets". Protein interaction network was analyzed via online Search Tool for the Retrieval of Interacting Genes (STRING v $10.0 \mathrm{http}: / /$ string-db.org).

\section{Statistical analysis}

The correlations between tumors, cells and pools in the in vivo and in vitro screen were analyzed by Pearson correlation analysis. In vitro and in vivo data are presented as the mean \pm s.d. (standard deviation) from three independent experiments. QPCR data are reported as mean \pm s.e. (standard error) of two independent experiments done in triplicate. Statistical analyses were performed using a two-tailed Student's $t$-test and one way ANOVA plus post-hoc Dunnett's test. In vivo read out of MMTV-NeuT transplantation assay was analyzed with a Mann-Whitney U test. Differences were considered statistically significant at $\mathrm{p}<0.05\left(^{*}\right), \mathrm{p}<0.01$ $(* *)$ and $\mathrm{p}<0.001(* * *)$.

\section{ACKNOWLEDGMENTS}

D. Bossi is recipient of a FUV fellowship. We thank P.G. Pelicci's group for the development of mouse model and A. De Rose for technical support in immunostaining.

We also thank A. Gobbi and M. Capillo for excellent support in animal work and L. Rotta for excellent sequencing support. We wish to thank all members of the Department of Experimental Oncology for discussion and reagents. We thank the Genomic Unit (IEO), the Mouse Facility (Cogentech), the DNA service (Cogentech) and the Cell Biology Unit (IEO).

\section{CONFLICTS OF INTEREST}

The authors certify that they have NO affiliations with or involvement in any organization or entity with any financial interest, or non-financial interest in the subject matter or materials discussed in this manuscript.

\section{GRANT SUPPORT}

This work was supported by the European Research Council Advanced Grant 341131 and Fondazione Veronesi Grant 2012.

\section{REFERENCES}

1. Bossi D, Cicalese A, Dellino GI, Luzi L, Riva L, D’Alesio C, Diaferia GR, Carugo A, Cavallaro E, Piccioni R, Barberis M, Mazzarol G, Testori A, Punzi S, Pallavicini I, Tosti G, et al. In Vivo Genetic Screens of Patient-Derived Tumors Revealed Unexpected Frailty of the Transformed Phenotype. Cancer Discov. 2016; 6:650-663.

2. Carugo A, Genovese G, Seth S, Nezi L, Rose JL, Bossi D, Cicalese A, Shah PK, Viale A, Pettazzoni PF, Akdemir KC, Bristow CA, Robinson FS, Tepper J, Sanchez N, Gupta $\mathrm{S}$, et al. In Vivo Functional Platform Targeting PatientDerived Xenografts Identifies WDR5-Myc Association as a Critical Determinant of Pancreatic Cancer. Cell Rep. 2016; 16:133-147.

3. Iskit S, Lieftink C, Halonen P, Shahrabi A, Possik PA, Beijersbergen RL and Peeper DS. Integrated in vivo genetic and pharmacologic screening identifies co-inhibition of EGRF and ROCK as a potential treatment regimen for triple-negative breast cancer. Oncotarget. 2016; 7:4285942872. doi: 10.18632/oncotarget.10230.

4. Pandyra AA, Mullen PJ, Goard CA, Ericson E, Sharma P, Kalkat M, Yu R, Pong JT, Brown KR, Hart T, Gebbia M, Lang KS, Giaever G, Nislow C, Moffat J and Penn LZ. 
Genome-wide RNAi analysis reveals that simultaneous inhibition of specific mevalonate pathway genes potentiates tumor cell death. Oncotarget. 2015; 6:26909-26921. doi: 10.18632/oncotarget.4817.

5. Baratta MG, Schinzel AC, Zwang Y, Bandopadhayay P, Bowman-Colin C, Kutt J, Curtis J, Piao H, Wong LC, Kung AL, Beroukhim R, Bradner JE, Drapkin R, Hahn WC, Liu $\mathrm{JF}$ and Livingston DM. An in-tumor genetic screen reveals that the BET bromodomain protein, BRD4, is a potential therapeutic target in ovarian carcinoma. Proc Natl Acad Sci U S A. 2015; 112:232-237.

6. Meacham CE, Lawton LN, Soto-Feliciano YM, Pritchard JR, Joughin BA, Ehrenberger T, Fenouille N, Zuber J, Williams RT, Young RA and Hemann MT. A genome-scale in vivo loss-of-function screen identifies Phf6 as a lineagespecific regulator of leukemia cell growth. Genes Dev. 2015; 29:483-488.

7. Possik PA, Muller J, Gerlach C, Kenski JC, Huang X, Shahrabi A, Krijgsman O, Song JY, Smit MA, Gerritsen B, Lieftink C, Kemper K, Michaut M, Beijersbergen RL, Wessels L, Schumacher TN, et al. Parallel in vivo and in vitro melanoma RNAi dropout screens reveal synthetic lethality between hypoxia and DNA damage response inhibition. Cell Rep. 2014; 9:1375-1386.

8. Wolf J, Muller-Decker K, Flechtenmacher C, Zhang F, Shahmoradgoli M, Mills GB, Hoheisel JD and Boettcher M. An in vivo RNAi screen identifies SALL1 as a tumor suppressor in human breast cancer with a role in CDH1 regulation. Oncogene. 2014; 33:4273-4278.

9. Beronja S, Janki P, Heller E, Lien WH, Keyes BE, Oshimori $\mathrm{N}$ and Fuchs E. RNAi screens in mice identify physiological regulators of oncogenic growth. Nature. 2013; 501:185-190.

10. Gargiulo G, Cesaroni M, Serresi M, de Vries N, Hulsman D, Bruggeman SW, Lancini C and van Lohuizen M. In vivo RNAi screen for BMI1 targets identifies TGF-beta/ BMP-ER stress pathways as key regulators of neural- and malignant glioma-stem cell homeostasis. Cancer Cell. 2013; 23:660-676.

11. Miller PG, Al-Shahrour F, Hartwell KA, Chu LP, Jaras M, Puram RV, Puissant A, Callahan KP, Ashton J, McConkey ME, Poveromo LP, Cowley GS, Kharas MG, Labelle M, Shterental S, Fujisaki J, et al. In Vivo RNAi screening identifies a leukemia-specific dependence on integrin beta 3 signaling. Cancer Cell. 2013; 24:45-58.

12. Lehtinen L, Ketola K, Makela R, Mpindi JP, Viitala $\mathrm{M}$, Kallioniemi $\mathrm{O}$ and Iljin $\mathrm{K}$. High-throughput RNAi screening for novel modulators of vimentin expression identifies MTHFD2 as a regulator of breast cancer cell migration and invasion. Oncotarget. 2013; 4:48-63. doi: 10.18632/oncotarget.756.

13. Iorns E, Ward TM, Dean S, Jegg A, Thomas D, Murugaesu N, Sims D, Mitsopoulos C, Fenwick K, Kozarewa I, Naceur-Lombarelli C, Zvelebil M, Isacke CM, Lord CJ, Ashworth A, Hnatyszyn HJ, et al. Whole genome in vivo RNAi screening identifies the leukemia inhibitory factor receptor as a novel breast tumor suppressor. Breast Cancer Res Treat. 2012; 135:79-91.

14. Possemato R, Marks KM, Shaul YD, Pacold ME, Kim D, Birsoy K, Sethumadhavan S, Woo HK, Jang HG, Jha AK, Chen WW, Barrett FG, Stransky N, Tsun ZY, Cowley GS, Barretina J, et al. Functional genomics reveal that the serine synthesis pathway is essential in breast cancer. Nature. 2011; 476:346-350.

15. Zuber J, McJunkin K, Fellmann C, Dow LE, Taylor MJ, Hannon GJ and Lowe SW. Toolkit for evaluating genes required for proliferation and survival using tetracyclineregulated RNAi. Nat Biotechnol. 2011; 29:79-83.

16. Zuber J, Shi J, Wang E, Rappaport AR, Herrmann H, Sison EA, Magoon D, Qi J, Blatt K, Wunderlich M, Taylor MJ, Johns C, Chicas A, Mulloy JC, Kogan SC, Brown P, et al. RNAi screen identifies Brd4 as a therapeutic target in acute myeloid leukaemia. Nature. 2011; 478:524-528.

17. Bric A, Miething C, Bialucha CU, Scuoppo C, Zender L, Krasnitz A, Xuan Z, Zuber J, Wigler M, Hicks J, McCombie RW, Hemann MT, Hannon GJ, Powers S and Lowe SW. Functional identification of tumor-suppressor genes through an in vivo RNA interference screen in a mouse lymphoma model. Cancer Cell. 2009; 16:324-335.

18. Meacham CE, Ho EE, Dubrovsky E, Gertler FB and Hemann MT. In vivo RNAi screening identifies regulators of actin dynamics as key determinants of lymphoma progression. Nat Genet. 2009; 41:1133-1137.

19. Zender L, Xue W, Zuber J, Semighini CP, Krasnitz A, Ma B, Zender P, Kubicka S, Luk JM, Schirmacher P, McCombie WR, Wigler M, Hicks J, Hannon GJ, Powers S and Lowe SW. An oncogenomics-based in vivo RNAi screen identifies tumor suppressors in liver cancer. Cell. 2008; 135:852-864.

20. Chung CY, Sun Z, Mullokandov G, Bosch A, Qadeer ZA, Cihan E, Rapp Z, Parsons R, Aguirre-Ghiso JA, Farias EF, Brown BD, Gaspar-Maia A and Bernstein E. Cbx8 Acts Non-canonically with Wdr5 to Promote Mammary Tumorigenesis. Cell Rep. 2016; 16:472-486.

21. Curigliano G. New drugs for breast cancer subtypes: targeting driver pathways to overcome resistance. Cancer Treat Rev. 2012; 38:303-310.

22. Shen $\mathrm{H}$ and Laird PW. Interplay between the cancer genome and epigenome. Cell. 2013; 153:38-55.

23. Vardabasso C, Hasson D, Ratnakumar K, Chung CY, Duarte $\mathrm{LF}$ and Bernstein E. Histone variants: emerging players in cancer biology. Cell Mol Life Sci. 2014; 71:379-404.

24. Easwaran H, Tsai HC and Baylin SB. Cancer epigenetics: tumor heterogeneity, plasticity of stem-like states, and drug resistance. Mol Cell. 2014; 54:716-727.

25. Nebbioso A, Carafa V, Benedetti R and Altucci L. Trials with 'epigenetic' drugs: an update. Mol Oncol. 2012; 6:657-682.

26. Xue Y, Wong J, Moreno GT, Young MK, Cote J and Wang W. NURD, a novel complex with both ATP-dependent 
chromatin-remodeling and histone deacetylase activities. Mol Cell. 1998; 2:851-861.

27. Zhang Y, LeRoy G, Seelig HP, Lane WS and Reinberg D. The dermatomyositis-specific autoantigen $\mathrm{Mi} 2$ is a component of a complex containing histone deacetylase and nucleosome remodeling activities. Cell. 1998; 95:279-289.

28. Zhang H, Stephens LC and Kumar R. Metastasis tumor antigen family proteins during breast cancer progression and metastasis in a reliable mouse model for human breast cancer. Clin Cancer Res. 2006; 12:1479-1486.

29. Toh Y and Nicolson GL. The role of the MTA family and their encoded proteins in human cancers: molecular functions and clinical implications. Clin Exp Metastasis. 2009; 26:215-227.

30. Fu J, Qin L, He T, Qin J, Hong J, Wong J, Liao L and Xu J. The TWIST/Mi2/NuRD protein complex and its essential role in cancer metastasis. Cell Res. 2011; 21:275-289.

31. Plotkin A, Volmar CH, Wahlestedt C, Ayad N and El-Ashry D. Transcriptional repression of ER through hMAPK dependent histone deacetylation by class I HDACs. Breast Cancer Res Treat. 2014; 147:249-263.

32. Lai AY and Wade PA. Cancer biology and NuRD: a multifaceted chromatin remodelling complex. Nat Rev Cancer. 2011; 11:588-596.

33. Polo SE, Kaidi A, Baskcomb L, Galanty Y and Jackson SP. Regulation of DNA-damage responses and cell-cycle progression by the chromatin remodelling factor CHD4. EMBO J. 2010; 29:3130-3139.

34. Smeenk G, Wiegant WW, Vrolijk H, Solari AP, Pastink A and van Attikum H. The NuRD chromatin-remodeling complex regulates signaling and repair of DNA damage. J Cell Biol. 2010; 190:741-749.

35. Luijsterburg MS, Acs K, Ackermann L, Wiegant WW, Bekker-Jensen S, Larsen DH, Khanna KK, van Attikum H, Mailand N and Dantuma NP. A new non-catalytic role for ubiquitin ligase RNF8 in unfolding higher-order chromatin structure. EMBO J. 2012; 31:2511-2527.

36. Barnabas $\mathrm{N}$ and Cohen D. Phenotypic and Molecular Characterization of MCF10DCIS and SUM Breast Cancer Cell Lines. Int J Breast Cancer. 2013; 2013:872743.

37. Dai M, Lu JJ, Guo W, Yu W, Wang Q, Tang R, Tang Z, Xiao Y, Li Z, Sun W, Sun X, Qin Y, Huang W, Deng WG and Wu T. BPTF promotes tumor growth and predicts poor prognosis in lung adenocarcinomas. Oncotarget. 2015; 6:33878-33892. doi: 10.18632/oncotarget.5302.

38. Floyd SR, Pacold ME, Huang Q, Clarke SM, Lam FC, Cannell IG, Bryson BD, Rameseder J, Lee MJ, Blake EJ, Fydrych A, Ho R, Greenberger BA, Chen GC, Maffa A, Del Rosario AM, et al. The bromodomain protein $\mathrm{Brd} 4$ insulates chromatin from DNA damage signalling. Nature. 2013; 498:246-250.

39. Kulawiec M, Safina A, Desouki MM, Still I, Matsui S, Bakin A and Singh KK. Tumorigenic transformation of human breast epithelial cells induced by mitochondrial DNA depletion. Cancer Biol Ther. 2008; 7:1732-1743.
40. Deng M, Wang J, Chen Y, Zhang L, Xie G, Liu Q, Zhang T, Yuan P and Liu D. Silencing cyclin-dependent kinase inhibitor 3 inhibits the migration of breast cancer cell lines. Mol Med Rep. 2016; 14:1523-1530.

41. Igci M, Kalender ME, Borazan E, Bozgeyik I, Bayraktar R, Bozgeyik E, Camci C and Arslan A. High-throughput screening of Sirtuin family of genes in breast cancer. Gene. 2016; 586:123-128.

42. Medina-Aguilar R, Marchat LA, Arechaga Ocampo E, Gariglio P, Garcia Mena J, Villegas Sepulveda N, Martinez Castillo $\mathrm{M}$ and Lopez-Camarillo C. Resveratrol inhibits cell cycle progression by targeting Aurora kinase A and Polo-like kinase 1 in breast cancer cells. Oncol Rep. 2016; 35:3696-3704.

43. Curry E, Green I, Chapman-Rothe N, Shamsaei E, Kandil S, Cherblanc FL, Payne L, Bell E, Ganesh T, Srimongkolpithak N, Caron J, Li F, Uren AG, Snyder JP, Vedadi M, Fuchter MJ, et al. Dual EZH2 and EHMT2 histone methyltransferase inhibition increases biological efficacy in breast cancer cells. Clin Epigenetics. 2015; 7:84.

44. Yang S, Quaresma AJ, Nickerson JA, Green KM, Shaffer SA, Imbalzano AN, Martin-Buley LA, Lian JB, Stein JL, van Wijnen AJ and Stein GS. Subnuclear domain proteins in cancer cells support the functions of RUNX2 in the DNA damage response. J Cell Sci. 2015; 128:728-740.

45. Liao YF, Wu YB, Long $\mathrm{X}$, Zhu SQ, Jin $\mathrm{C}, \mathrm{Xu} J \mathrm{~J}$ and Ding JY. High level of BRD4 promotes non-small cell lung cancer progression. Oncotarget. 2016; 7:9491-9500. doi: 10.18632/oncotarget.7068.

46. Dar AA, Nosrati M, Bezrookove V, de Semir D, Majid S, Thummala S, Sun V, Tong S, Leong SP, Minor D, Billings PR, Soroceanu L, Debs R, Miller JR, 3rd, Sagebiel RW and Kashani-Sabet M. The role of BPTF in melanoma progression and in response to BRAF-targeted therapy. J Natl Cancer Inst. 2015; 107.

47. Torchy MP, Hamiche A and Klaholz BP. Structure and function insights into the NuRD chromatin remodeling complex. Cell Mol Life Sci. 2015; 72:2491-2507.

48. O'Shaughnessy A and Hendrich B. CHD4 in the DNAdamage response and cell cycle progression: not so NuRDy now. Biochem Soc Trans. 2013; 41:777-782.

49. Sperlazza J, Rahmani M, Beckta J, Aust M, Hawkins E, Wang SZ, Zu Zhu S, Podder S, Dumur C, Archer K, Grant $\mathrm{S}$ and Ginder GD. Depletion of the chromatin remodeler CHD4 sensitizes AML blasts to genotoxic agents and reduces tumor formation. Blood. 2015; 126:1462-1472.

50. Chudnovsky Y, Kim D, Zheng S, Whyte WA, Bansal M, Bray MA, Gopal S, Theisen MA, Bilodeau S, Thiru P, Muffat J, Yilmaz OH, Mitalipova M, Woolard K, Lee J, Nishimura R, et al. ZFHX4 interacts with the NuRD core member CHD4 and regulates the glioblastoma tumorinitiating cell state. Cell Rep. 2014; 6:313-324.

51. De P, Carlson JH, Wu H, Marcus A, Leyland-Jones B and Dey N. Wnt-beta-catenin pathway signals metastasisassociated tumor cell phenotypes in triple negative breast 
cancers. Oncotarget. 2016; 7:43124-43149. doi:10.18632/ oncotarget.8988.

52. Low JK, Webb SR, Silva AP, Saathoff H, Ryan DP, Torrado M, Brofelth M, Parker BL, Shepherd NE and Mackay JP. CHD4 is a Peripheral Component of the Nucleosome Remodeling and Deacetylase Complex. J Biol Chem. 2016.

53. Cardiff RD and Muller WJ. Transgenic mouse models of mammary tumorigenesis. Cancer Surv. 1993; 16:97-113.

54. Pece S, Tosoni D, Confalonieri S, Mazzarol G, Vecchi M, Ronzoni S, Bernard L, Viale G, Pelicci PG and Di Fiore PP. Biological and molecular heterogeneity of breast cancers correlates with their cancer stem cell content. Cell. 2010; 140:62-73.

55. Soule HD, Maloney TM, Wolman SR, Peterson WD, Jr., Brenz R, McGrath CM, Russo J, Pauley RJ, Jones $\mathrm{RF}$ and Brooks SC. Isolation and characterization of a spontaneously immortalized human breast epithelial cell line, MCF-10. Cancer Res. 1990; 50:6075-6086.

56. Vermeulen K, Van Bockstaele DR and Berneman ZN. The cell cycle: a review of regulation, deregulation and therapeutic targets in cancer. Cell Prolif. 2003; 36:131-149.

57. Buddaseth S, Gottmann W, Blasczyk R and Huyton T. Dysregulation of cell cycle control caused by overexpression of the oncogene pp32r1 (ANP32C) and the Tyr $>$ His mutant pp32r1Y140H. Biochim Biophys Acta. 2013; 1833:1212-1221.

58. Gurpinar E and Vousden KH. Hitting cancers' weak spots: vulnerabilities imposed by p53 mutation. Trends Cell Biol. 2015; 25:486-495.

59. Jung YS, Qian Y and Chen X. Examination of the expanding pathways for the regulation of p21 expression and activity. Cell Signal. 2010; 22:1003-1012.

60. Furia L, Pelicci PG and Faretta M. A computational platform for robotized fluorescence microscopy (I): high-content imagebased cell-cycle analysis. Cytometry A. 2013; 83:333-343.

61. Furia L, Pelicci PG and Faretta M. A computational platform for robotized fluorescence microscopy (II): DNA damage, replication, checkpoint activation, and cell cycle progression by high-content high-resolution multiparameter image-cytometry. Cytometry A. 2013; 83:344-355.

62. Scholzen T and Gerdes J. The Ki-67 protein: from the known and the unknown. J Cell Physiol. 2000; 182:311-322.
63. Jemal A, Bray F, Center MM, Ferlay J, Ward E and Forman D. Global cancer statistics. CA Cancer J Clin. 2011; 61:69-90.

64. Denslow SA and Wade PA. The human Mi-2/NuRD complex and gene regulation. Oncogene. 2007; 26:5433-5438.

65. Vargo-Gogola T and Rosen JM. Modelling breast cancer: one size does not fit all. Nat Rev Cancer. 2007; 7:659-672.

66. Kennecke H, Yerushalmi R, Woods R, Cheang MC, Voduc D, Speers $\mathrm{CH}$, Nielsen $\mathrm{TO}$ and Gelmon K. Metastatic behavior of breast cancer subtypes. J Clin Oncol. 2010; 28:3271-3277.

67. Voduc KD, Cheang MC, Tyldesley S, Gelmon K, Nielsen TO and Kennecke H. Breast cancer subtypes and the risk of local and regional relapse. J Clin Oncol. 2010; 28:1684-1691.

68. Langdon SP and Cameron DA. Pertuzumab for the treatment of metastatic breast cancer. Expert Rev Anticancer Ther. 2013; 13:907-918.

69. Widakowich C, de Castro G, Jr., de Azambuja E, Dinh P and Awada A. Review: side effects of approved molecular targeted therapies in solid cancers. Oncologist. 2007; 12:1443-1455.

70. Gartel AL, Najmabadi F, Goufman E and Tyner AL. A role for E2F1 in Ras activation of p21(WAF1/CIP1) transcription. Oncogene. 2000; 19:961-964.

71. Muller WJ, Sinn E, Pattengale PK, Wallace R and Leder P. Single-step induction of mammary adenocarcinoma in transgenic mice bearing the activated c-neu oncogene. Cell. 1988; 54:105-115.

72. Nolan-Stevaux O, Tedesco D, Ragan S, Makhanov M, Chenchik A, Ruefli-Brasse A, Quon K and Kassner PD. Measurement of Cancer Cell Growth Heterogeneity through Lentiviral Barcoding Identifies Clonal Dominance as a Characteristic of Tumor Engraftment. PLoS One. 2013; 8:e67316.

73. Langmead B, Trapnell C, Pop M and Salzberg SL. Ultrafast and memory-efficient alignment of short DNA sequences to the human genome. Genome Biol. 2009; 10:R25.

74. Liu Z, Wang Y, Wang S, Zhang J, Zhang F and Niu Y. Nek2C functions as a tumor promoter in human breast tumorigenesis. Int J Mol Med. 2012; 30:775-782. 